\title{
High-Throughput Analysis of Lidocaine in Pharmaceutical Formulation by Capillary Zone Electrophoresis Using Multiple Injections in a Single Run
}

\author{
Andressa C. Valese, ${ }^{1}$ Daniel A. Spudeit, ${ }^{2}$ Maressa D. Dolzan, ${ }^{2}$ Lizandra C. Bretanha, ${ }^{1}$ \\ Luciano Vitali, ${ }^{2}$ and Gustavo A. Micke ${ }^{2}$ \\ ${ }^{1}$ Department of Food Science Technologies, Federal University of Santa Catarina, Florianopolis, SC, Brazil \\ ${ }^{2}$ Departamento de Química, CFM, UFSC, Campus Universitário, Trindade, CP 476, 88040-900 Florianópolis, SC, Brazil
}

Correspondence should be addressed to Gustavo A. Micke; gustavo.micke@ufsc.br

Received 29 November 2015; Revised 20 January 2016; Accepted 21 January 2016

Academic Editor: Mohamed Abdel-Rehim

Copyright ( 2016 Andressa C. Valese et al. This is an open access article distributed under the Creative Commons Attribution License, which permits unrestricted use, distribution, and reproduction in any medium, provided the original work is properly cited.

\begin{abstract}
This paper reports the development of a subminute separation method by capillary zone electrophoresis in an uncoated capillary using multiple injection procedure for the determination of lidocaine in samples of pharmaceutical formulations. The separation was performed in less than a minute leading to doing four injections in a single run. The cathodic electroosmotic flow contributed to reducing the analyses time. The background electrolyte was composed of $20 \mathrm{mmol} \mathrm{L}^{-1}$ 2-amino-2-(hydroxymethyl)-1,3-propanediol and $40 \mathrm{mmol} \mathrm{L}^{-1} 2$-( $\mathrm{N}$-morpholino)ethanesulfonic acid at $\mathrm{pH}$ 6.1. The internal standard used was benzylamine. Separations were performed in a fused uncoated silica capillary $(32 \mathrm{~cm}$ total length, $23.5 \mathrm{~cm}$ effective length, and $50 \mu \mathrm{m}$ internal diameter) with direct UV detection at $200 \mathrm{~nm}$. Samples and standards were injected hydrodynamically using $40 \mathrm{mbar} / 3 \mathrm{~s}$ interspersed with spacer electrolyte using $40 \mathrm{mbar} / 7 \mathrm{~s}$. The electrophoretic system was operated under constant voltage of $30 \mathrm{kV}$ with positive polarity on the injection side. The evaluation of some analytical parameters of the method showed good linearity $\left(r^{2}>0.999\right)$, a limit of detection $0.92 \mathrm{mg} \mathrm{L}^{-1}$, intermediate precision better than $3.2 \%$ (peak area), and recovery in the range of $92-102 \%$.
\end{abstract}

\section{Introduction}

In recent years, capillary electrophoresis (CE) has gained attention of the international scientific community, as an alternative powerful technique for the separation and analysis of compounds of industrial, pharmaceutical, clinical, and environmental interest [1-3]. Some of the features that make the $\mathrm{CE}$ an analytical technique of great interest are its wide applicability, being possible to analyze different kinds of samples, the low cost, small amount of waste generated, small sample demand, versatility and especially simplicity in handling, and the speed of experiments that may perform the separation of many compounds in minutes or even in a few seconds [4]. According to recent papers published, the development of rapid methods using CE could be based on strategies as the use of reduced capillary length, application of high electric field, injection at the short-end of the capillary closest to the detector, use of multiple injections in a single run, or even the combinations of all of these strategies [5-8].

The development of simple and fast analytical methods using $\mathrm{CE}$ can be further facilitated when using simulation software to select experimental conditions as buffering capacity and conductivity of the medium, electromigration dispersion (EMD) for the analytes, among others. This allows developing an analytical methodology with minimum number of experiments, which can significantly reduce the time spent on this step as shown in different studies described in the literature using the PeakMaster ${ }^{\circledR}$ software [8-13].

Lidocaine is a drug commonly employed as local anesthetic and antiarrhythmic substance present in many commercially available pharmaceutical formulations [14]. Its monitoring in these samples is performed using several methods as high-performance liquid-chromatography (HPLC) with ultraviolet detection (UV) [14-17], HPLC system with 
UV detection used with no chromatographic column connected [18], capillary electrophoresis (CE) with mass spectrometry (MS) detection [19], and CE with UV detection [5].

Within the papers cited above only one describes the method development exploring the CE potential to create a fast method to determine lidocaine in environmental samples. Geiser and coauthors [5] show a method for separation of lidocaine in less than a minute as a result of exploration of many possibilities for fast CE separation methods, including application of a high electric field through a reduced capillary, short-end injection, multiple sample injections, and use of a dynamically coated capillary to increase the electroosmotic flow (EOF). The background electrolyte (BGE) used was composed of $100 \mathrm{mM}$ trisphosphate at $\mathrm{pH}$ 2.5. Considering an uncoated capillary, the EOF value is practically negligible in this $\mathrm{pH}$ and thus does not affect the analysis time of the separation of lidocaine. However, the EOF of an uncoated fused silica capillary is one of the characteristics of the CE that could be explored to reduce the separation time of lidocaine. In this type of capillary, the EOF increases at sigmoidal shape with increasing $\mathrm{pH}$ of the $\mathrm{BGE}$ [11]. Thus, at $\mathrm{pH}$ above 5, the EOF cathodic of an uncoated capillary could aid in reducing the separation time of lidocaine, since the mobility of it is added to EOF mobility, that is, separation on the co-EOF mode.

Given the above, the aim of this study is to develop a fast method by capillary zone electrophoresis (CZE) exploring the strategies of multiple injection in a single run and the co-EOF mode to determine lidocaine in the pharmaceutical formulations and also employ the PeakMaster software to select the composition of BGE and evaluate some performance parameters of the developed method to determine lidocaine in the samples.

\section{Experimental}

2.1. Chemicals and Solutions. The analytical standard of lidocaine hydrochloride and the reagents 2-amino-2(hydroxymethyl)-1,3-propanediol (TRIS), 2-(N-morpholino)ethanesulfonic acid (MES), and benzylamine were purchased from Sigma-Aldrich (St. Louis, USA). Stock solutions of lidocaine $1000 \mathrm{mg} \mathrm{L}^{-1}$ and benzylamine 648 $\mathrm{mg} \mathrm{L}^{-1}$ (internal standard, IS) were prepared in deionized water and stored in a freezer until they are used. The BGE for analysis of lidocaine in the samples was composed of $20 \mathrm{mmol} \mathrm{L}^{-1}$ TRIS and $40 \mathrm{mmol} \mathrm{L}^{-1}$ MES at $\mathrm{pH} 6.1$ prepared in deionized water. Deionized water (Milli-Q, Millipore, Bedford, MA, United States) was used to prepare all the solutions.

2.2. Instrumentation. All experiments were conducted on CE System (7100 Capillary Electrophoresis System, Agilent Technologies, Palo Alto, USA) equipped with a diode array detector set at $200 \mathrm{~nm}$ (direct detection), a temperature control device (set at $25^{\circ} \mathrm{C}$ ), and data treatment software (HP ChemStation ${ }^{\circledR}$ rev A.06.01). Standards and samples were introduced at the long-end of the capillary and injected using hydrodynamic pressure according to the following steps: $40 \mathrm{mbar} / 3 \mathrm{~s}$ (sample or standard); $40 \mathrm{mbar} / 7 \mathrm{~s}$ (spacer electrolyte); $40 \mathrm{mbar} / 3 \mathrm{~s}$ (sample or standard); $40 \mathrm{mbar} / 7 \mathrm{~s}$ (spacer electrolyte); $40 \mathrm{mbar} / 3 \mathrm{~s}$ (sample or standard); $40 \mathrm{mbar} / 7 \mathrm{~s}$ (spacer electrolyte); and $40 \mathrm{mbar} / 3 \mathrm{~s}$ (sample or standard). The electrophoretic system was operated under positive polarity on the injection side and constant voltage conditions of $30 \mathrm{kV}$. For all experiments an uncoated fused silica capillary was used purchased from Polymicro Technologies (Phoenix, United States) measuring $32 \mathrm{~cm}(23.5 \mathrm{~cm}$ effective length $) \times 50 \mu \mathrm{m}$ i.d. $\times 375 \mu \mathrm{m}$ o.d. Initially, the capillary was conditioned by a pressure flush of $1.0 \mathrm{~mol} \mathrm{~L}^{-1}$ of sodium hydroxide (30 min), water $(30 \mathrm{~min})$, and BGE (10 $\mathrm{min})$. Between runs, the capillary was rinsed for 0.5 min with the BGE.

2.3. Samples. A total of four different samples of pharmaceutical formulations commercially available containing lidocaine as active pharmaceutical ingredient (API) were analyzed: two samples in the form of liquid and two ointments. Liquid samples were appropriately diluted in deionized water before injections. Ointment samples were previously weighted ( $200 \mathrm{mg})$, solubilized in $100.0 \mathrm{~mL}$ of deionized water using volumetric flasks, and then diluted in water before injections. After dilutions, the samples were diluted with IS solution (final concentration $64.8 \mathrm{mg} \mathrm{L}^{-1}$ ) and injected into the capillary electrophoresis system.

\section{Results and Discussion}

3.1. Method Optimization. The development of the method for separation of lidocaine by CZE was based on its structural characteristics (Figure 1(a)). Lidocaine shows chromophores groups that permit employing the direct UV detection mode. Then, the components of BGE should not absorb UV radiation. The selection of $\mathrm{pH}$ of the BGE is based on effective mobility versus $\mathrm{pH}$ curves (Figure $1(\mathrm{~b})$ ) constructed using the ion mobility $\left(23.6 \times 10^{-9} \mathrm{~m}^{2} \mathrm{~V}^{-1} \mathrm{~s}^{-1}\right)$ and $\mathrm{p} K_{a}$ (7.85) values of lidocaine obtained from the literature [20]. It is of interest to use a $\mathrm{pH}$ equal to or less than 6.5 because lidocaine is highly ionized (cationic form) contributing to a fast separation. However, in a capillary uncoated the EOF is cathodic and increases with the $\mathrm{pH}$ of BGE contributing to reducing separation time of lidocaine in the co-EOF mode. Thus, considering the mobility of lidocaine and EOF the $\mathrm{pH}$ selected was 6.0. TRIS was selected as the BGE coion since it has an ionic mobility close to the lidocaine ionic mobility (Figure 2(b)), contributing to minimizing its EMD. However, TRIS does not exhibit good buffering capacity at $\mathrm{pH}$ around 6. Thus, MES ( $\mathrm{p} K_{a}$ 6.15) was selected as counterion because it supplies buffering capacity to the BGE. The optimum concentration of BGE components was TRIS $20 \mathrm{mmol} \mathrm{L}^{-1}$ and MES $40 \mathrm{mmol} \mathrm{L}^{-1}$. The system parameters predicted by PeakMaster software for this BGE were $\mathrm{pH}$ 6.0, ionic strength $20 \mathrm{mmol} \mathrm{L}^{-1}$, conductivity $0.09 \mathrm{~S} \mathrm{~m}^{-1}$, and buffer capacity $23.5 \mathrm{mmol} \mathrm{L}^{-1}$. All these values are appropriate for good characteristics of the CZE method contributing to 
<smiles>CCN(CC)CC(=O)Nc1c(C)cccc1C</smiles>

(a)

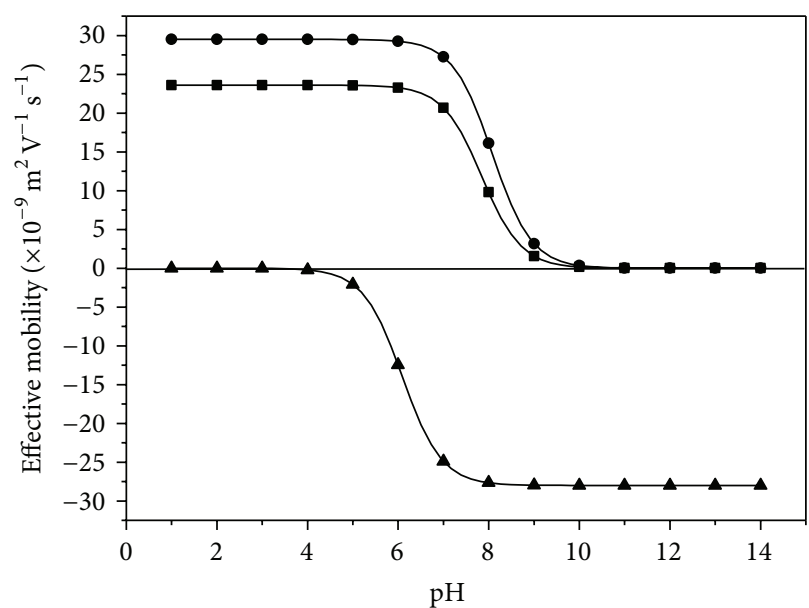

(b)

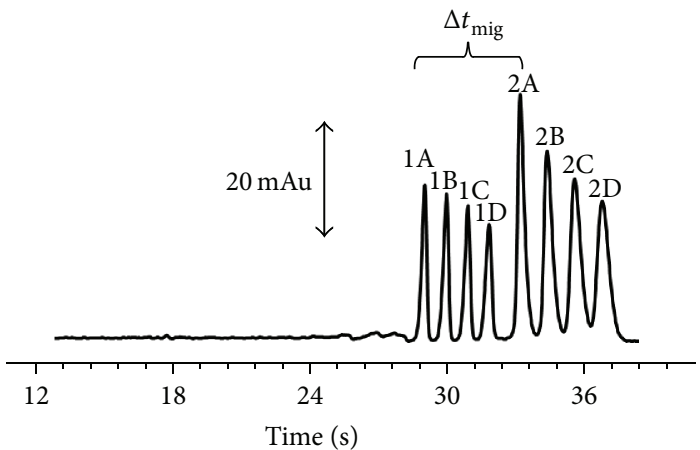

(c)

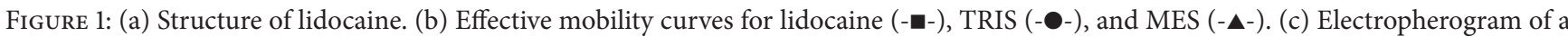
pharmaceutical formulation using the optimized method by CZE with multiple injections. Peaks: 1: benzylamine (IS); 2: lidocaine; A, B, C, and $\mathrm{D}$ represent the first, second, third, and fourth injection, respectively. BGE composed by TRIS $20 \mathrm{mmol} \mathrm{L}^{-1}$ and $\mathrm{MES} 40 \mathrm{mmol} \mathrm{L}^{-1}$ at $\mathrm{pH}$ 6.1. EOF mobility measured $33.1 \times 10^{-9} \mathrm{~m}^{2} \mathrm{~V}^{-1} \mathrm{~s}^{-1}$.

maintaining constant mobility for lidocaine and EOF along separations. The electromigration dispersion for lidocaine was 1.2 and the internal standard chosen for the method was benzylamine due to its ionic mobility close to lidocaine and absorptivity of UV radiation.

Using the multiple injection procedure is necessary to calculate the sample capacity $\left(\eta_{s}\right)$. For the proposed method the migration time of the fast migrating compound $\left(t_{\text {migl }}\right)$ is of the benzylamine (IS) and its migration time is larger than the time window $\left(\Delta t_{\text {mig }}\right)$ between the lidocaine and benzylamine. Then, $\eta_{s}$ can be calculated employing the following equation [6]:

$$
\eta_{s}=\frac{\Delta t_{\mathrm{mig}}}{12 \sigma},
$$

where $\sigma$ represent the broadest peak and can be calculated from the width at $50 \%$ of the peak height $\left(\sigma=w_{50 \%} / 2.35\right)$. Using the values of $\Delta t_{\mathrm{mig}} 0.1000 \mathrm{~min}$ and $w_{50 \%} 0.0047 \mathrm{~min}$, $\eta_{s}$ calculated was 4.2 . Then, as the value obtained was not an integer, we deemed it wise to make the maximum number of injected samples four in a single run. Between each one of the four samples injected spacer electrolyte ( $40 \mathrm{mBar} / 7 \mathrm{~s})$ was used for separation of the applied plugs. The experimental electropherogram obtained of a pharmaceutical formulation using the optimized method by CZE with multiple injections is shown in Figure 1(c). It is possible to observe the peaks of the lidocaine and benzylamine related to four samples injected with an extremely short time of separation, less than one minute, in a single run.

3.2. Method Figures of Merit. The performance evaluation of the proposed method for determining lidocaine by CZE in pharmaceutical formulations was performed according to ICH guidelines [21]. The parameters analyzed were linearity, limit of detection (LOD) and quantification (LOQ), repeatability (instrumental and intraday), intermediate precision, and selectivity.

The results for parameters evaluated are shown in Table 1. The range of linearity and characteristics of analytical curve were appropriate to lidocaine analysis in samples of pharmaceutical formulations. Furthermore, the LOD and LOQ were less than $3.1 \mathrm{mg} \mathrm{L}^{-1}$ allowing the quantification of lidocaine in samples. The precision results were better than $3.2 \%$ (intermediate) for peak area and $1.0 \%$ (intermediate) for 


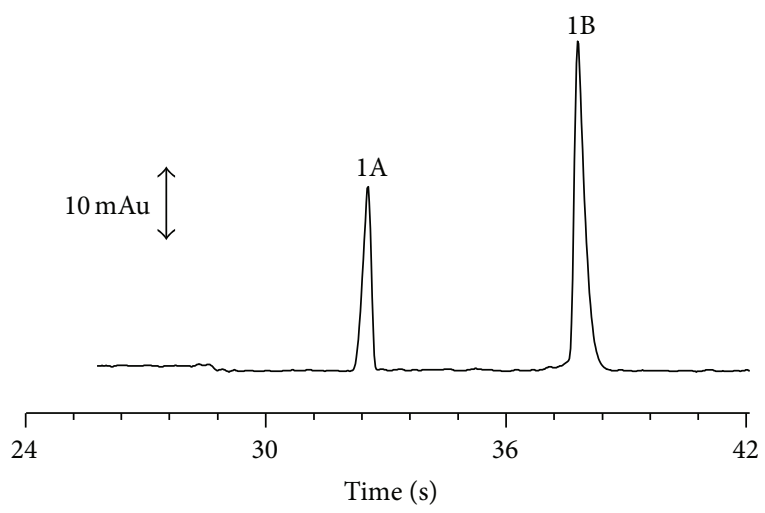

(a)

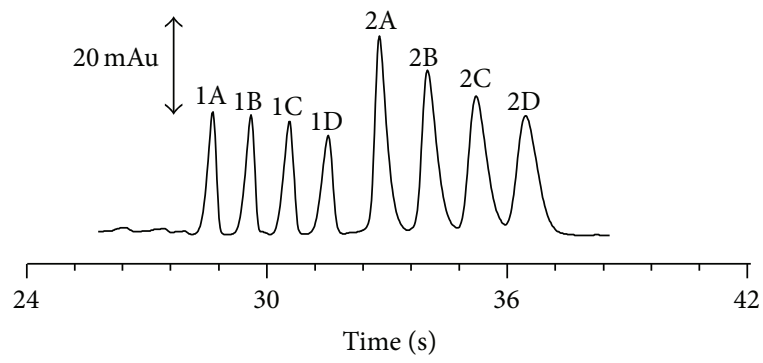

(c)

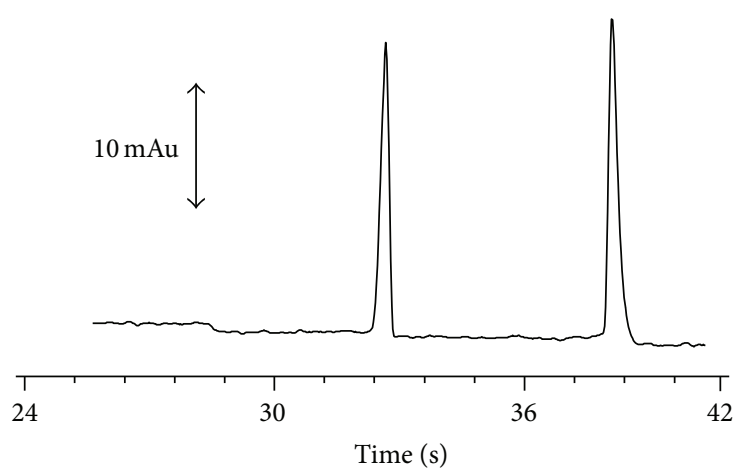

(b)

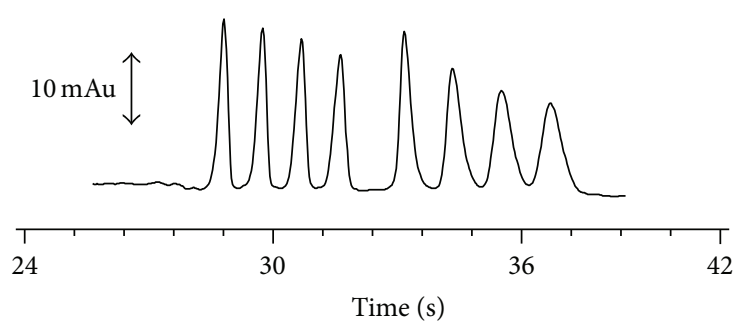

(d)

Figure 2: Comparison of single and multiple injections for standard solution ((a) and (c)) and a sample ((b) and (d)). Peaks: 1: benzylamine (IS); 2: lidocaine; A, B, C, and D represent the first, second, third, and fourth injection, respectively.

migration time. The recovery experiments were made in three levels of concentration showing range of 92 to $102 \%$, indicating selectivity of the proposed method for lidocaine analysis in the samples. Furthermore, the slopes of the standard addition curve for ointment $(0.0184 \pm 0.001)$ and the external calibration curve $(0.0186 \pm 0.0004)$ were very close suggesting that the method has no matrix effect for the analyzed samples.

3.3. Comparison between Multiple and Single Injections. The multiple injection is a tool that makes it possible to increase the throughput for electrophoretic analysis using a commercial equipment without any modification. However, the effect of multiple injections on the performance of the method should be taken into account. To evaluate these effects on the performance of the proposed methods a sample of pharmaceutical product and a standard solution were injected several times using both single and multiple injections (Figure 2).

By quickly inspecting Figure 2, it is possible to notice that the multiple injections affect the peak shape.

A visual inspection of Figure 2 suggests that the peak shape is affected using the MI mode. This fact could be related to the effective length that is different for each plug injected, leading to difference in the values for the electromigrations dispersion. The fact that the analytes on the last plug will pass through the first plugs of samples and spacers also contributes to the loss in performance when comparing the single and multiple injections. But, on the other hand, these losses in performance are constant and do not affect the quantification parameters (Table 2).

3.4. Determination of Lidocaine in Samples. A total of four different pharmaceutical formulations were analyzed using the proposed CZE method with multiple injections and the results are shown in Table 3 . The concentrations of the lidocaine determined were close to the nominal concentration for the samples analyzed. The difference between the determined and declared values can be related to several possibilities like bad packaging, exposure to a sun light, and so on, factors that could affect the amount of lidocaine in the sample. The separation was very fast and no interfering peaks from matrix samples were detected. The instrumental throughput of the proposed method was 15 injections per hour using the multiple injection procedure that represents 60 injections per hour (each run has four injections); as a consequence, the analytical frequency using multiple injection mode increases twice comparing to the single injection procedure (30 injections per hour).

\section{Conclusions}

A new fast method to analyze lidocaine by CZE in an uncoated capillary using multiple injections and co-EOF mode was developed. The PeakMaster software was an important tool for selecting the BGE composition. The performance parameters evaluated for the proposed method show good 
TABLE 1: Performance parameters of the method by CZE for analysis of lidocaine.

\begin{tabular}{|c|c|}
\hline \multicolumn{2}{|l|}{ Parameters } \\
\hline Number of plates $\left(\mathrm{N} \mathrm{m}^{-1}\right)$ & $67.000-100.000$ \\
\hline Resolution (range for neighboring peaks) & $2.00-2.5$ \\
\hline Linearity-calibration range $\left(\mathrm{mg} \mathrm{L}^{-1}\right)^{1}$ & $10-50$ \\
\hline Linearity-slope $\left(\mathrm{L} \mathrm{mg}^{-1}\right)^{1}$ & 0.0186 \\
\hline Slope standard deviation ${ }^{1}$ & $3.9 \times 10^{-4}$ \\
\hline Linearity-intercept ${ }^{1}$ & 0.006 \\
\hline Intercept standard deviation ${ }^{1}$ & 0.0002 \\
\hline$r^{1}$ & 0.999 \\
\hline$F$ & 7858 \\
\hline $\operatorname{LOD}\left(\mathrm{mg} \mathrm{L}^{-1}\right)^{2}$ & 0.92 \\
\hline $\mathrm{LOQ}\left(\mathrm{mg} \mathrm{L}^{-1}\right)^{2}$ & 3.1 \\
\hline Instrumental precision, RSD (\%)-peak area ${ }^{3}$ & $1.2-2.8(1.0-3.0)$ \\
\hline $\begin{array}{l}\text { Instrumental precision, RSD (\%)-migration } \\
\text { time }^{3}\end{array}$ & $0.51-0.55(0.4-1.3)$ \\
\hline Intra-day precision, RSD (\%)-peak area ${ }^{4}$ & $2.7-2.9(2.5-3.5)$ \\
\hline $\begin{array}{l}\text { Intra-day precision, RSD (\%)-migration } \\
\text { time }\end{array}$ & $0.25-1.2(0.68-1.6)$ \\
\hline Intermediate precision, RSD (\%)-peak area ${ }^{4}$ & $2.6-3.2$ \\
\hline $\begin{array}{l}\text { Intermediate precision, RSD (\%)-migration } \\
\text { time }^{4}\end{array}$ & $0.83-0.95$ \\
\hline $\begin{array}{l}\text { Recovery }(\%)^{5} \text {, added } 8.0 \mathrm{mg} \mathrm{L}^{-1}, \text { found } \\
8.2 \mathrm{mg} \mathrm{L}^{-1}\end{array}$ & 102 \\
\hline $\begin{array}{l}\text { Recovery }(\%)^{5} \text {, added } 16.0 \mathrm{mg} \mathrm{L}^{-1}, \text { found } \\
14.7 \mathrm{mg} \mathrm{L}^{-1}\end{array}$ & 92 \\
\hline $\begin{array}{l}\text { Recovery }(\%)^{5} \text {, added } 24.0 \mathrm{mg} \mathrm{L}^{-1}, \text { found } \\
23.5 \mathrm{mg} \mathrm{L}^{-1}\end{array}$ & 98 \\
\hline $\begin{array}{l}{ }^{1} \text { Six levels of concentration }(n=3) \text { genuine replica } \\
{ }^{2} \text { LOD and LOQ calculated using the equations LOI } \\
=(10 \times s) / S \text {, where } s \text { is the intercept standard dev } \\
\text { of the analytical curve equation, respectively. }{ }^{3} \text { Valu } \\
\text { and a sample, outside and inside the brackets, respec } \\
\text { to four peaks injected }(\mathrm{P} 1, \mathrm{P} 2, \mathrm{P} 3 \text {, and } \mathrm{P} 4)(n= \\
\text { a standard and a sample, outside and inside the bra } \\
\text { range relative to three levels of concentration testec } \\
\text { an ointment sample. }\end{array}$ & $\begin{array}{l}\text { s, injected in triplicate. } \\
=(3.3 \times s) / S \text { and LOQ } \\
\text { tion and } S \text { is the slope } \\
\text { referents to a standard } \\
\text { vely. RSD range relative } \\
\text {. }{ }^{4} \text { Values referents to } \\
\text { kets, respectively. RSD } \\
(n=9) .{ }^{5} \text { Recovery for }\end{array}$ \\
\hline
\end{tabular}

TABLE 2: Performance comparison for single and multiple injections.

\begin{tabular}{lcc}
\hline & \multicolumn{2}{c}{ RSD (\%) } \\
& Multiple injections & Single injections \\
\hline Peak area & $0.9-1.5(1.1-2.4)$ & $0.9(2.5)$ \\
Peak width $^{1,2}$ & $1.2-2.2(0.66-1.6)$ & $1.04(3.4)$ \\
Peak high $^{1,2}$ & $1-2.3(0.8-1.2)$ & $0.77(1.8)$ \\
\hline
\end{tabular}

${ }^{1}$ Values referents to a standard and a sample, outside and inside the brackets, respectively. RSD range relative to four peaks injected (P1, P2, P3, and P4) $(n=10) .{ }^{2}$ Values calculated for lidocaine.

results for LOD, LOQ, precision, and recovery indicating that the method is useful for determination of lidocaine in pharmaceutical formulations. The CZE separation obtained with this method, reaching around 60 injections per hour, provides an interesting alternative for routine analysis due to its fast separation, simplicity, and low residue amounts.
TABLE 3: Lidocaine quantification in the pharmaceutical formulations by CZE method.

\begin{tabular}{|c|c|c|}
\hline Sample & $\begin{array}{c}\text { Nominal } \\
\text { concentration }^{1}(\mathrm{mg})\end{array}$ & $\begin{array}{c}\text { Found } \\
\text { concentration }(\mathrm{mg})\end{array}$ \\
\hline (1) Ointment ${ }^{2}$ & 50 & $62.8 \pm 0.01$ \\
\hline (2) Ointment ${ }^{2}$ & 25 & $29.19 \pm 0.03$ \\
\hline (3) Liquid & 50 & $65.58 \pm 0.01$ \\
\hline (4) Liquid & 4 & $3.70 \pm 0.01$ \\
\hline
\end{tabular}

\section{Conflict of Interests}

The authors declare that there is no conflict of interests regarding the publication of this paper.

\section{Acknowledgments}

The authors wish to thank the Conselho Nacional de Desenvolvimento Científico e Tecnológico $(\mathrm{CNPq}$, Brazil) and Coordenação de Aperfeiçoamento de Pessoal de Nível Superior (CAPES, Brazil) for their financial support.

\section{References}

[1] G. A. Micke, E. P. Moraes, J. P. S. Farah, and M. F. M. Tavares, "Assessing the separation of neutral plant secondary metabolites by micellar electrokinetic chromatography," Journal of Chromatography A, vol. 1004, no. 1-2, pp. 131-143, 2003.

[2] R. Jabeen, D. Payne, J. Wiktorowicz, A. Mohammad, and J. Petersen, "Capillary electrophoresis and the clinical laboratory," Electrophoresis, vol. 27, no. 12, pp. 2413-2438, 2006.

[3] A. A. Alhusban, M. C. Breadmore, and R. M. Guijt, "Capillary electrophoresis for monitoring bioprocesses," Electrophoresis, vol. 34, no. 11, pp. 1465-1482, 2013.

[4] J. L. Felhofer, L. Blanes, and C. D. Garcia, "Recent developments in instrumentation for capillary electrophoresis and microchipcapillary electrophoresis," Electrophoresis, vol. 31, no. 15, pp. 2469-2486, 2010.

[5] L. Geiser, S. Rudaz, and J.-L. Veuthey, "Decreasing analysis time in capillary electrophoresis: validation and comparison of quantitative performances in several approaches," Electrophoresis, vol. 26, no. 12, pp. 2293-2302, 2005.

[6] A. Amini, H. Lodén, C. Pettersson, and T. Arvidsson, "Principles for different modes of multiple-injection CZE," Electrophoresis, vol. 29, no. 19, pp. 3952-3958, 2008.

[7] H. Lodén and A. Amini, "Quantification of buserelin in a pharmaceutical product by multiple-injection CZE," Electrophoresis, vol. 28, no. 10, pp. 1548-1556, 2007.

[8] L. Vitali, B. L. Horst, M. Heller, V. T. Fávere, and G. A. Micke, "Using multiple short-end injections to develop fast electrophoretic separations-applications in iodide analysis," Journal of Chromatography A, vol. 1218, no. 28, pp. 4586-4591, 2011.

[9] A. C. O. Costa, L. da Silva Perfeito, M. F. M. Tavares, and G. A. Micke, "Determination of sorbate and benzoate in beverage samples by capillary electrophoresis-optimization of the method with inspection of ionic mobilities," Journal of Chromatography A, vol. 1204, no. 1, pp. 123-127, 2008. 
[10] D. A. Spudeit, M. Piovezan, M. D. Dolzan et al., "Simultaneous determination of free and total glycerol in biodiesel by capillary electrophoresis using multiple short-end injection," Electrophoresis, vol. 34, no. 24, pp. 3333-3340, 2013.

[11] L. Vitali, F. Della Betta, A. C. O. Costa et al., "New multilayer coating using quaternary ammonium chitosan and $\kappa$ carrageenan in capillary electrophoresis: application in fast analysis of betaine and methionine," Talanta, vol. 123, pp. 4553, 2014.

[12] L. Vitali, A. C. Valese, M. S. Azevedo et al., "Development of a fast and selective separation method to determine histamine in tuna fish samples using capillary zone electrophoresis," Talanta, vol. 106, pp. 181-185, 2013.

[13] A. C. O. Costa, J. L. da Costa, F. G. Tonin, M. F. M. Tavares, and G. A. Micke, "Development of a fast capillary electrophoresis method for determination of creatinine in urine samples," Journal of Chromatography A, vol. 1171, no. 1-2, pp. 140-143, 2007.

[14] L. Zivanovic, M. Zecevic, S. Markovic, S. Petrovic, and I. Ivanovic, "Validation of liquid chromatographic method for analysis of lidocaine hydrochloride, dexamethasone acetate, calcium dobesilate, buthylhydroxyanisol and degradation product hydroquinone in suppositories and ointment," Journal of Chromatography A, vol. 1088, no. 1-2, pp. 182-186, 2005.

[15] M. Pendela, G. Kahsay, I. Baekelandt, A. Van Schepdael, and E. Adams, "Simultaneous determination of lidocaine hydrochloride, hydrocortisone and nystatin in a pharmaceutical preparation by RP-LC," Journal of Pharmaceutical and Biomedical Analysis, vol. 56, no. 3, pp. 641-644, 2011.

[16] B. Zargar and A. Hatamie, "Hollow fiber liquid based microextraction combined with high-performance liquidchromatography for the analysis of lidocaine in biological and pharmaceutical samples," Analytical Methods, vol. 6, no. 8, pp. 2506-2511, 2014.

[17] J. M. Lemus Gallego and J. Pérez Arroyo, "Comparison of HPLC and multivariate regression methods for hydrocortisone and lidocaine analysis of pharmaceutical preparations," Analytical and Bioanalytical Chemistry, vol. 374, no. 2, pp. 282-288, 2002.

[18] K. Wiberg, A. Hagman, and S. P. Jacobsson, "Rapid determination of lidocaine solutions with non-column chromatographic diode array UV spectroscopy and multivariate calibration," Journal of Pharmaceutical and Biomedical Analysis, vol. 30, no. 5, pp. 1575-1586, 2003.

[19] L. Geiser, S. Rudaz, and J.-L. Veuthey, "Validation of capillary electrophoresis-mass spectrometry methods for the analysis of a pharmaceutical formulation," Electrophoresis, vol. 24, no. 17, pp. 3049-3056, 2003.

[20] B. Gas, P. Coufal, M. Jaroš, J. Muzikář, and I. Jelínek, “Optimization of background electrolytes for capillary electrophoresis: I. Mathematical and computational model," Journal of Chromatography A, vol. 905, no. 1-2, pp. 269-279, 2001.

[21] ICH, Validation of Analytical Procedures: Text and Methodology Q2(R1), Guidance, 1994, 2005. 

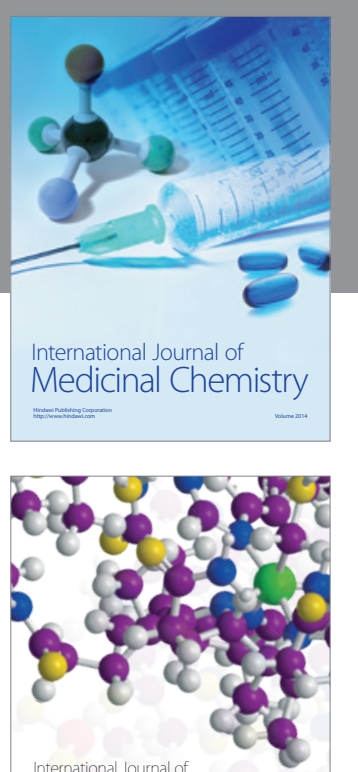

Carbohydrate Chemistry

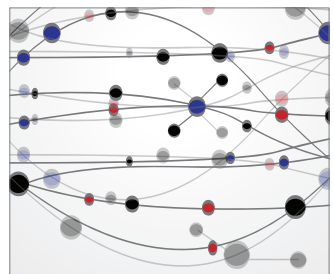

The Scientific World Journal
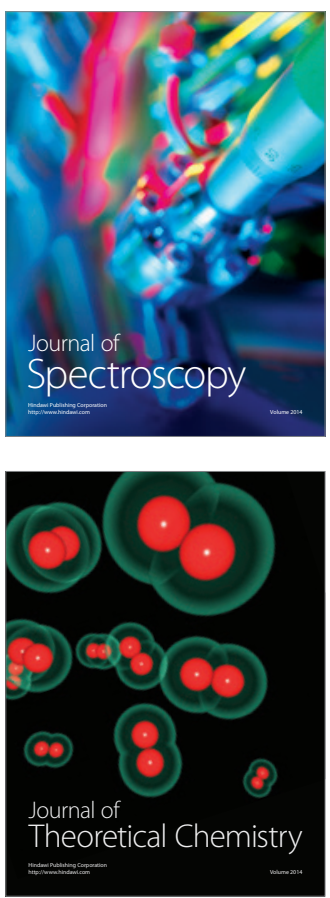
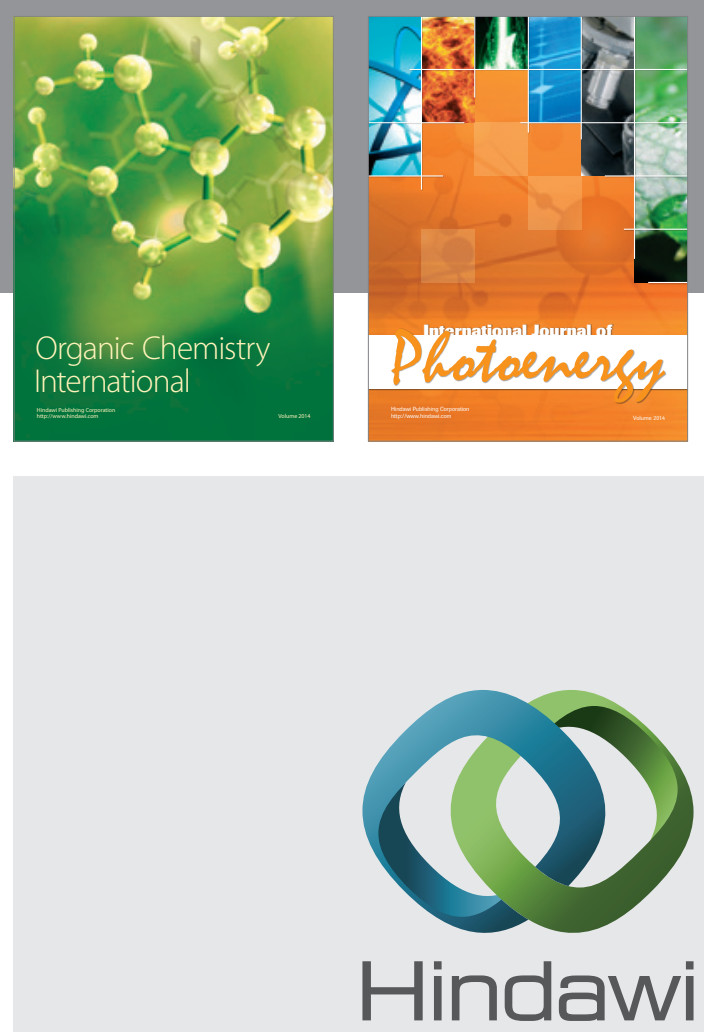

Submit your manuscripts at

http://www.hindawi.com

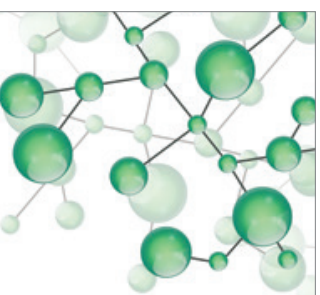

International Journal of

Inorganic Chemistry

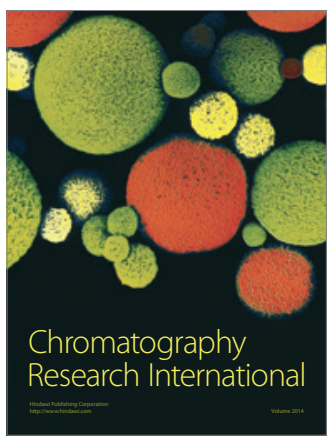

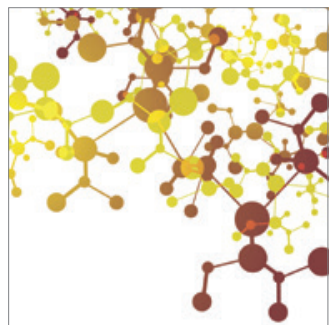

Applied Chemistry
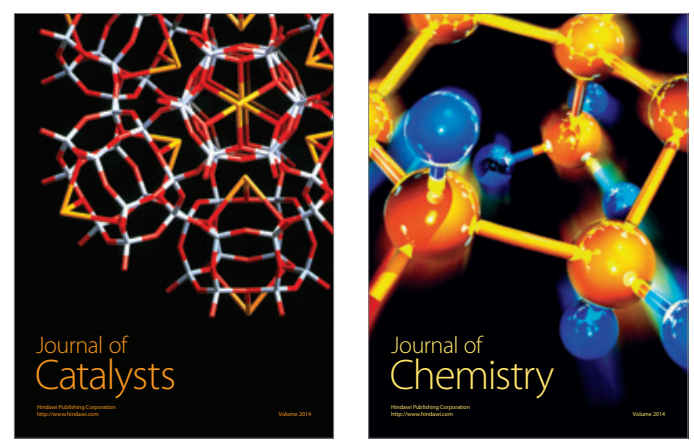
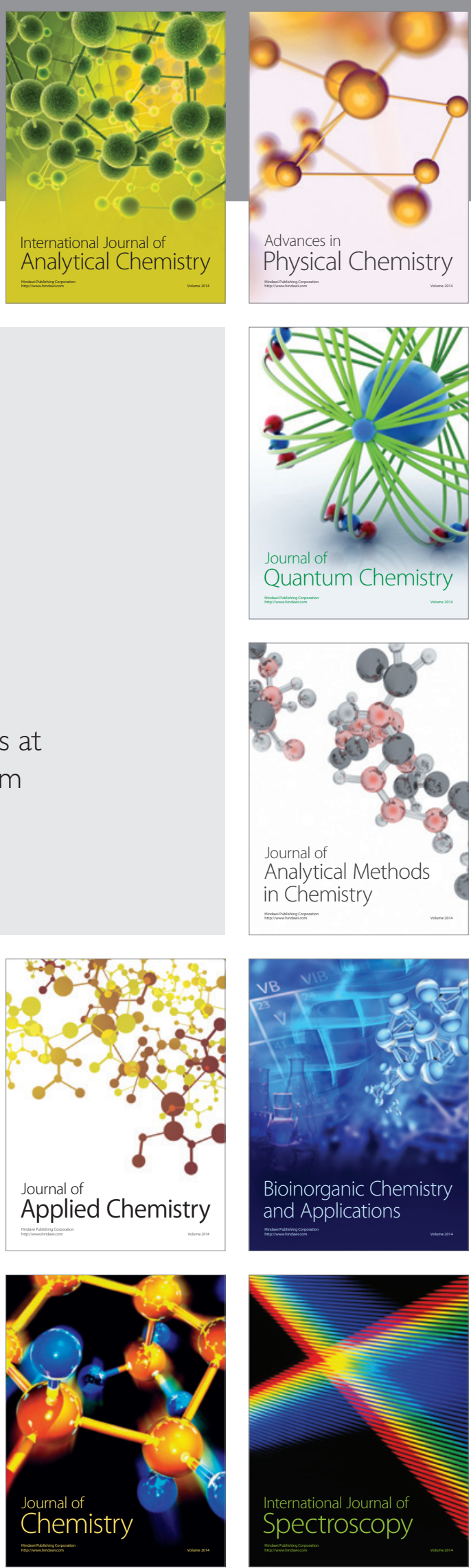